ORIGINAL ARTICLE

\title{
Frequent overexpression of epidermal growth factor receptor (EGFR) in mammary high grade ductal carcinomas with myoepithelial differentiation
}

\author{
T Shien, T Tashiro, M Omatsu, T Masuda, K Furuta, N Sato, S Akashi-Tanaka, M Uehara, \\ E Iwamoto, T Kinoshita, T Fukutomi, H Tsuda, T Hasegawa
}

J Clin Pathol 2005;58:1299-1304. doi: 10.1136/icp.2005.026096

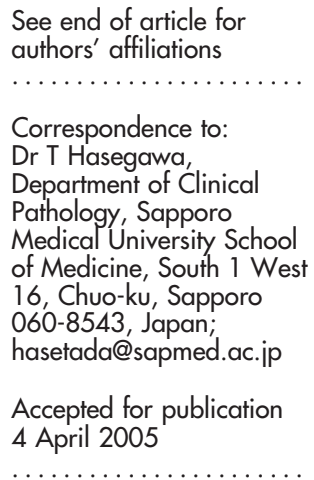

\begin{abstract}
Aims: To evaluate the expression of common biological markers and the epidermal growth factor receptor (EGFR) in mammary high grade ductal carcinomas with myoepithelial differentiation (DCMDs).

Materials/methods: Thirty DCMDs were clinicopathologically and immunohistochemically analysed and compared with 36 control cases of high grade conventional invasive ductal carcinoma (IDC).

Results: EGFR, HER2/neu, oestrogen receptor, progesterone receptor, and p53 expression was seen in 21 , one, three, four, and 20 of the 30 DCMDs, compared with eight, nine, 18, 17, and five of the 36 conventional IDCs $(p<0.05)$, respectively. In 16 of the 30 DCMDs, metastases were found in the brain, lung, bone, and liver, within a maximum of 47 months (mean, 13.9) after initial surgery, whereas only four of the 36 conventional IDCs metastasised to the lung and bone within a maximum of 27 months (mean, 18.0) after initial surgery $(p=0.0001)$. There was a significant difference in disease free survival between DCMD and conventional IDC $(p=0.001)$. EGFR was frequently overexpressed in DCMD compared with conventional IDC, whereas the expression of HER2/neu and hormone receptors was lower in DCMD. Fluorescent in situ hybridisation revealed that the mean EGFR to chromosome 7 centromere (CEP7) ratio of the 24 DCMD cases available for evaluation was 1.03, and EGFR gene amplification was not detected in the 21 DCMD cases with EGFR overexpression.

Conclusion: Immunohistochemistry for myoepithelial markers and EGFR is useful for the accurate diagnosis and molecular target treatment of high grade DCMD.
\end{abstract}

\begin{abstract}
A pproximately $2-18 \%$ of ductal carcinomas of the breast are immunohistochemically positive for myoepithelial markers, such as cytokeratin 14, vimentin, $\alpha$ smooth muscle actin, S-100 protein, and calponin. ${ }^{1-3}$ Matrix producing carcinomas (MPCs) and carcinosarcomas (CSs) are representative mixed epithelial and myoepithelial metaplastic carcinomas. ${ }^{45}$ In addition, we have previously described a subset of invasive ductal carcinomas (IDCs) with a large central acellular zone showing myoepithelial differentiation. ${ }^{67}$ In routine diagnostic practice, we have noticed that these high grade ductal carcinomas with myoepithelial differentiation (DCMDs) showed less frequent expression of hormone receptors and HER2/neu but an increased frequency of p53 overexpression, in accordance with a previous study. As for adjuvant treatment, anthracycline based chemotherapy was used in most patients. The role of adjuvant chemotherapy is unclear, because sufficiently large observational randomised series of these rare neoplasms have not yet been reported.

Some of the most promising agents for the treatment and prevention of oestrogen receptor (ER) negative breast cancer are growth factor receptor tyrosine kinase inhibitors. The epidermal growth factor receptor (EGFR) is one of a family of four closely related receptors (EGFR or erbB1, HER2/neu or erbB2, HER3 or erbB3, and HER4 or erbB4) that use tyrosine kinase activity as the signal transduction trigger. The EGFR pathway contributes to several processes involved in tumour survival and growth, including cell proliferation and inhibition of apoptosis, angiogenesis, and metastasis, thus making it an attractive target for cancer prevention and treatment. EGFR is expressed in $7-36 \%$ of breast carcinomas. ${ }^{9-11}$ The prognosis in patients with EGFR+/ER- breast carcinoma is
\end{abstract}

reportedly poor, ${ }^{10}{ }^{12}$ but the histological features of breast carcinomas with EGFR overexpression remain unclear.

\begin{abstract}
"Some of the most promising agents for the treatment and prevention of oestrogen receptor negative breast cancer are growth factor receptor tyrosine kinase inhibitors"
\end{abstract}

To elucidate the relation between the histological features and the expression of common biological markers and EGFR, we evaluated the clinicopathological and immunohistochemical characteristics of patients with DCMD, and also analysed EGFR gene amplification status by means of fluorescence in situ hybridisation (FISH).

\section{MATERIALS AND METHODS}

\section{Case selection}

Thirty haematoxylin and eosin stained tissue samples from patients diagnosed with DCMD including IDC with a large central acellular zone $(n=20), \operatorname{MPC}(n=5)$, and CS $(n=5)$ were independently reviewed by two pathologists ( $\mathrm{TH}$ and TS). All patients were histologically diagnosed as having high grade (grade 3) carcinoma, and had undergone mastectomy or breast conservation treatment at the National Cancer Centre Hospital, Tokyo, Japan between 1982 and 2003. IDCs with a large central acellular zone were histologically defined

Abbreviations: CS, carcinosarcoma; DCMD, ductal carcinoma with myoepithelial differentiation; DFS, disease free survival; EGFR, epidermal growth factor receptor; ER, oestrogen receptor; FISH, fluorescence in situ hybridisation; IDC, invasive ductal carcinoma; MPC, matrix producing carcinoma; PBS, phosphate buffered saline; PgR, progesterone receptor 

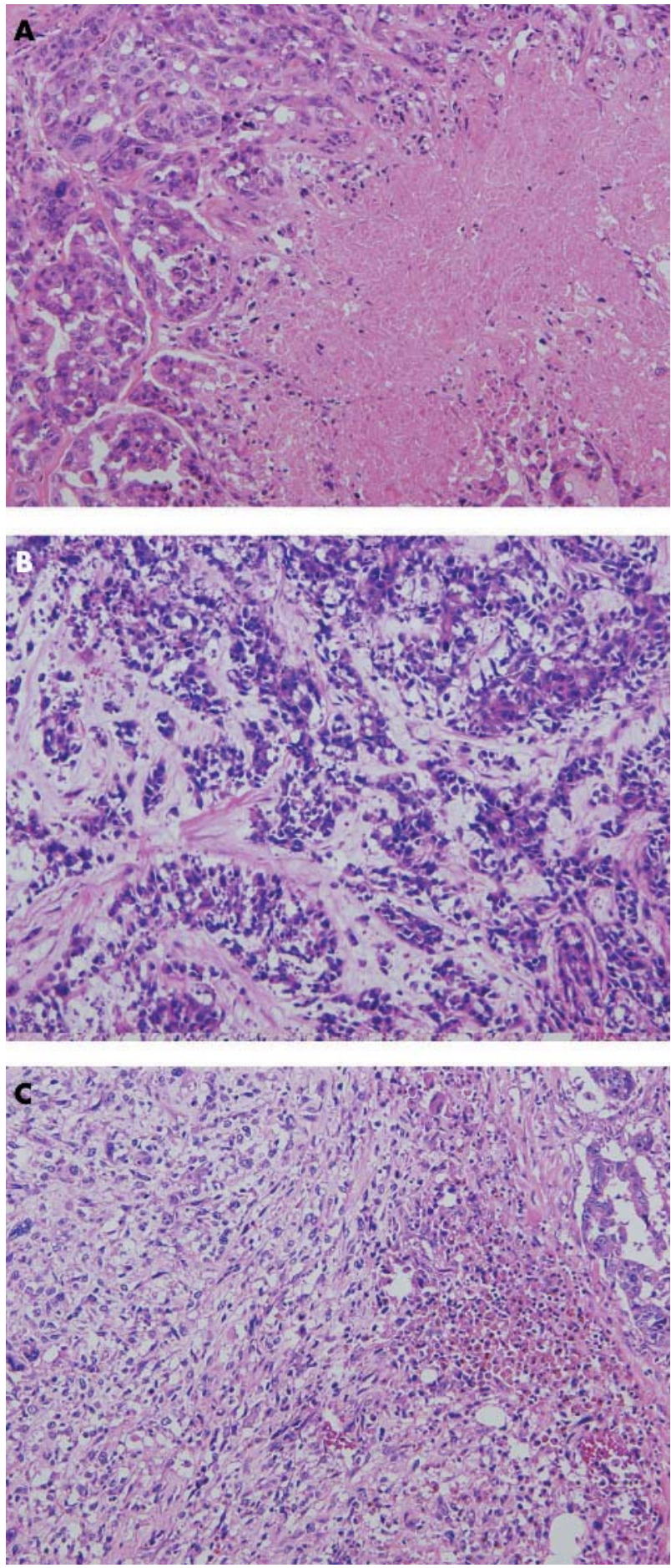

Figure 1 High grade ductal carcinoma with myoepithelial differentiation: $(A)$ invasive ductal carcinoma with a large central acellular zone, (B) matrix producing carcinoma, (C) carcinosarcoma (spindle cell carcinoma). Haematoxylin and eosin stain.

as IDC with foci of tissue infarction in the central zone covering more than $30 \%$ of the tumour tissue area, accompanied by a varying degree of myxoid stromal matrix at the periphery (fig lA). These carcinomas showed no features of CS, osseous or cartilaginous metaplasia, or MPC. MPCs showed infiltrating growth, mixed often with heterologous myoepithelial elements, from areas of bland chondroid and osseous differentiation to frank sarcomatous components (fig 1B). CSs had myoepithelial components composed of malignant, undifferentiated spindle cells that formed part of the tumour (fig 1C).

DCMDs were diagnosed based on the demonstration of specific cytoplasmic immunoreactivity for one or more myoepithelial marker. Immunopositivity for S-100 protein (fig 2A), $\alpha$ smooth muscle actin (fig 2B), and keratin 14 was seen in 23,30, and 19 of the 30 cases, respectively. All three groups of tumours showed a similar immunohistochemical staining pattern for myoepithelial markers.

As a control group, samples from 36 patients with conventional IDC who were treated and followed in our hospital at the same time between 1982 and 2003 and matched for patient age, histological grade, tumour size, and lymph node status were selected from the pathology files, although it is not clear that this control group is large enough in view of the recognised heterogeneity between and within breast cancers. Clinical and follow up information was obtained by reviewing the medical records.

\section{Immunohistochemistry}

Immunostaining for HER2/neu, ER, progesterone receptor (PgR), and p53 was performed on $4 \mu \mathrm{m}$ formalin fixed, paraffin wax embedded tissue sections using the labelled streptavidin biotin method (DakoCytomation, Glostrup, Denmark). Table 1 lists the specifications of the primary antibodies used in our study. After routine dewaxing and rehydration, the sections were moistened with phosphate buffered saline (PBS; pH 7.4). They were pretreated in an autoclave at $121^{\circ} \mathrm{C}$ for 10 minutes in $10 \mu \mathrm{mol} /$ litre citrate buffer ( $\mathrm{pH}$ 6.0), before being incubated with all antibodies, except for anti-S-100, in an automated immunostaining system (i6000 ${ }^{\mathrm{TM}}$; BioGenex, San Ramon, California, USA) for 30 minutes. Immunohistochemical staining for EGFR was performed according to the instructions included with the EGFR detection system (EGFR pharmDx kit; DakoCytomation).

The immunohistochemical results for the HER2/neu, ER, PgR, p53, and EGFR specific antibodies were judged by two observers using a multiheaded microscope. A consensus judgment was adopted as the proper immunohistochemical score of the tumour based on strength: 0 , negative; $1+$, weak staining; $2+$, moderate staining; $3+$, strong staining. The distribution of positive cells was also graded in an effort to assess the diffuse or focal nature of the positive cells as sporadic (positive cells, $\leqslant 10 \%$ ), focal $(10-50 \%$ positive cells), or diffuse (positive cells, $\geqslant 50 \%$ ). For ER, PgR, and p53, tumour nuclear staining in more than $10 \%$ of cells was evaluated as positive, regardless of intensity. For HER2/neu and EGFR, immunohistochemical scores of $2+$ and 3+ with a focal to diffuse distribution were considered to be positive.

\section{Fluorescence in situ hybridisation}

FISH was carried out according to the manufacturer's instructions. Briefly, after dewaxing, the slides were immersed in $0.2 \mathrm{~N} \mathrm{HCl}$ for 20 minutes and pretreatment solution (Vysis, Downers Grove, Illinois, USA) for 30 minutes at $80^{\circ} \mathrm{C}$, then digested with protease for 60 minutes at $37^{\circ} \mathrm{C}$, washed in $1 \times$ PBS for five minutes at room temperature, fixed in $10 \%$ formaldehyde for 10 minutes at room temperature, washed in $1 \times$ PBS for five minutes at room temperature, placed into prewarmed denaturation solution (Vysis) for five minutes at $72^{\circ} \mathrm{C}$, and dehydrated by immersing in $70 \%, 85 \%$, and $100 \%$ ethanol for one minute each at room temperature.

For interphase FISH, the slides were subjected to hybridisation with the LSI EGFR/chromosome 7 centromere (CEP7) dual colour probe (Vysis). A Spectrum Orange labelled EGFR specific probe and a Spectrum Green labelled centromeric 

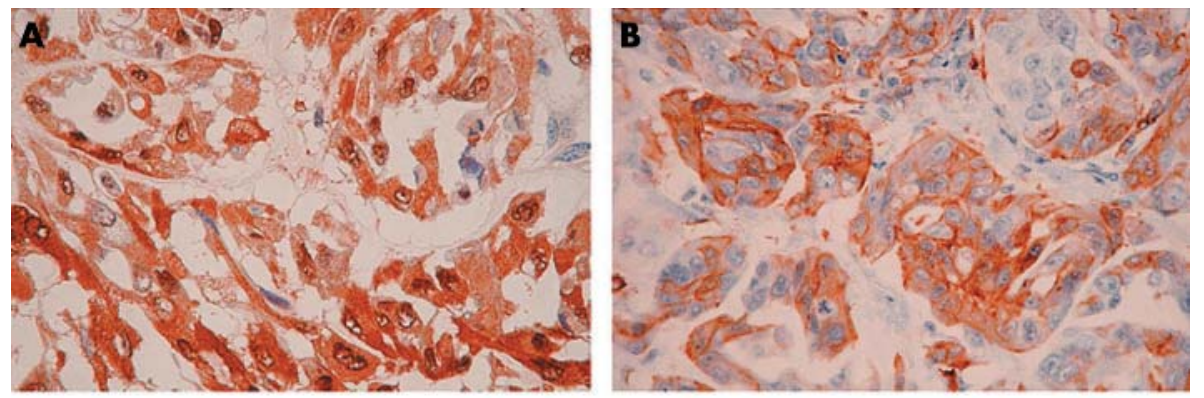

Figure 2 Immunohistochemical findings in a high grade ductal carcinoma with myoepithelial differentiation: the expression of (A) S100 , (B) $\alpha$ smooth muscle actin, (C) epidermal growth factor receptor, and (D) p53. Immunoperoxidase stain.
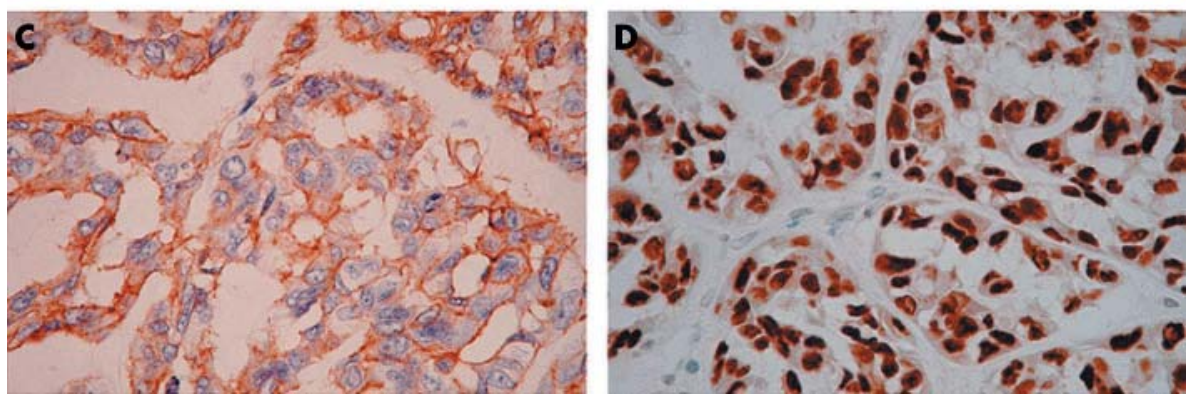

probe that hybridises to the centromeric region of the chromosome were used as controls to normalise copy numbers for chromosome 7 . The FISH probe mix $(10 \mu \mathrm{l})$ was added to the sample area of the slides at $45^{\circ} \mathrm{C}$. The slides were coverslipped, sealed with rubber cement, and incubated at $37^{\circ} \mathrm{C}$ for 48 hours in a humidified chamber. They were then washed in post-hybridisation wash buffer at $72^{\circ} \mathrm{C}$. Subsequently, $10 \mu \mathrm{l}$ of 4,6-diamidine-2-phenylindole dihydrochloride (DAPI; Vysis) counterstain was placed on the slide and the slide was coverslipped. After hybridisation, all slides were maintained at $-20^{\circ} \mathrm{C}$ in the dark. Hybridisation signals were visualised with an epifluorescence microscope, and images were captured on a CCD camera. For each specimen, the number of orange EGFR signals was counted for the 60 nuclei, and the mean EGFR copy number was calculated by dividing the total number of EGFR signals by 60. The mean green CEP7 copy number was also calculated by dividing the total number of CEP7 signals by 60 . The EGFR : CEP7 ratio was also calculated for each specimen by dividing the total number of orange EGFR signals by the total number of green CEP7 signals. A ratio of $>2.0$ was defined as EGFR DNA amplification.

Table 1 Profiles of antibodies used in our study

\begin{tabular}{|c|c|c|}
\hline $\begin{array}{l}\text { Antigen/antibody } \\
\text { (dilution) }\end{array}$ & Source & Pretreatment \\
\hline $\begin{array}{l}\text { S-100 protein } \\
(1 / 2000)^{*}\end{array}$ & $\begin{array}{l}\text { DakoCyłomation, Glostrup, } \\
\text { Denmark }\end{array}$ & None \\
\hline SMA (1A4; $1 / 100)$ & DakoCytomation & Autoclave \\
\hline $\begin{array}{l}\text { Keratin } 14 \text { (LLOO2; } \\
1 / 50 \text { ) }\end{array}$ & Ylem, Rome, Italy & Autoclave \\
\hline $\begin{array}{l}\text { EGFR (2-18C9; } \\
\text { prediluted) }\end{array}$ & DakoCytomation & Proteinase $\mathrm{K}$ \\
\hline HER2/neu $(1 / 100)^{*}$ & DakoCytomation & Autoclave \\
\hline ER (1D5; 1/50) & DakoCytomation & Autoclave \\
\hline $\operatorname{PgR}(1 \mathrm{~A} 6 ; 1: 50)$ & $\begin{array}{l}\text { Novocastra, Newcastle upon } \\
\text { Tyne, UK }\end{array}$ & Autoclave \\
\hline p53 (DO7; 1/100) & DakoCytomation & Autoclave \\
\hline
\end{tabular}

*Polyclonal antibody.

EGFR, epidermal growth factor receptor; ER, oestrogen receptor; PgR, progesterone receptor; SMA, smooth muscle actin.
Table 2 Clinicopathological difference between the study and control patients

\begin{tabular}{|c|c|c|c|}
\hline & $\mathrm{DCMD}(\mathrm{n}=30)$ & CIDC $(n=36)$ & $\mathrm{p}$ Value \\
\hline \multicolumn{4}{|l|}{ Age (years) } \\
\hline$<50$ & 14 & 17 & NS \\
\hline$>50$ & 16 & 19 & \\
\hline Mean & 50.1 & 49.2 & \\
\hline Histological grade 3 & 30 & 36 & \\
\hline \multicolumn{4}{|c|}{ Tumour size } \\
\hline$<3 \mathrm{~cm}$ & 10 & 26 & \\
\hline$>3 \mathrm{~cm}$ & 20 & 10 & NS \\
\hline Mean & $2.7 \mathrm{~cm}$ & $2.7 \mathrm{~cm}$ & \\
\hline \multicolumn{4}{|l|}{ LN metastases } \\
\hline Yes & $13(43.3 \%)$ & $16(44.4 \%)$ & \\
\hline No & $17(56.7 \%)$ & $20(55.6 \%)$ & NS \\
\hline \multicolumn{4}{|l|}{ Distant metastases } \\
\hline+ & $16(53.3 \%)$ & $4(11.0 \%)$ & \\
\hline- & $14(46.7 \%)$ & $32(89.0 \%)$ & 0.0001 \\
\hline
\end{tabular}

\section{Statistical analysis}

Statistical differences were calculated using the $\chi^{2}$ test or Fisher's exact test. Disease free survival (DFS) curves were plotted using the Kaplan-Meier method, and significant differences between the survival curves were calculated using the log rank test. Differences of $p<0.05$ were considered significant.

\section{RESULTS}

\section{Patient characteristics}

Table 2 shows the clinicopathological characteristics of the patients with DCMD $(\mathrm{n}=30)$ and controls $(\mathrm{n}=36)$. All patients with DCMD were female, with an average age at the time of initial diagnosis of 50.1 years (range, 26-77). All the control patients (with high grade conventional IDC) were female, with an average age at the time of initial diagnosis of 49.2 years (range, $28-77$ ). None of the patients with DCMD or the control subjects had other cancers or endocrinological disorders. Each patient with DCMD presented with a palpable mass measuring between 1.2 and $5.2 \mathrm{~cm}$ (mean, 2.7) at the greatest diameter, whereas the control patients had a palpable mass measuring between 0.6 and $8.0 \mathrm{~cm}$ 


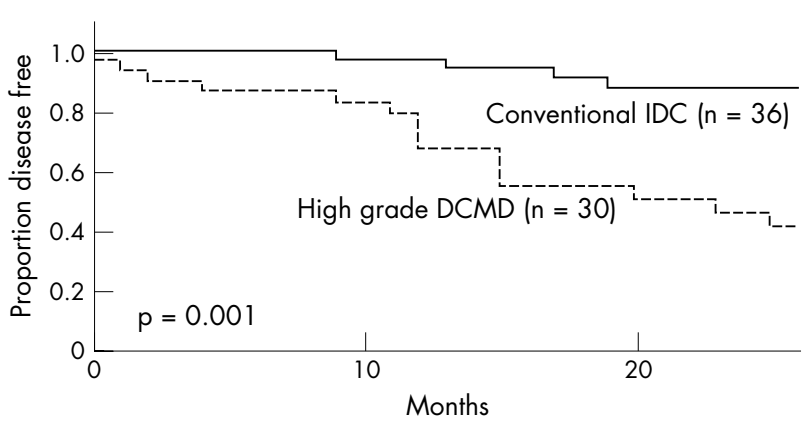

Figure 3 Disease free survival curves plotted for high grade ductal carcinomas with myoepithelial differentiation $(D C M D ; n=30)$ and conventional invasive carcinomas (IDC; $\mathrm{n}=36$ ).

(mean, 2.7) at the greatest diameter. Lymph node metastases were seen in 13 of the 30 patients with DCMD and in 16 of the 36 control subjects. There were no significant differences in age, histological grade, tumour size, or lymph node status between the two groups. Sixteen of the 30 patients with DCMD developed distant metastases within a maximum of 47 months (mean, 13.9) after surgery ( $p=0.0001) ; 29$ metastases were detected in the brain (nine), lungs (eight), bone (five), liver (three), skin (one), stomach (one), spleen (one), and soft tissue (one) during a follow up period ranging from two to 122 months (mean, 40.9). In contrast, only four of the 36 control patients developed metastases within 27 months (mean, 18.0) after surgery (two each in the bone and lung). Figure 3 shows the DFS curves. There was a significant difference in DFS between the DCMD and control groups $(\mathrm{p}=0.001)$.

\section{Immunohistochemical features}

EGFR overexpression was detected in 21 of the 30 DCMD cases-12 of 20 patients with IDCs having a large central acellular zone, all five patients with MPC, and four of the five patients with CS (fig 2C)-and in eight of the 36 control subjects (table 3). HER2/neu overexpression was found in only one of the 30 patients with DCMD and in nine of the 36 controls. Positive reactions in the nuclei for ER and PgR were seen in three and four patients with DCMD, and in 18 and 17 of the controls, respectively. Immunoreactivity for p53 was seen in 20 of the 30 patients with DCMD and in five of the 36 control patients (fig 2D). When comparing the DCMD and control groups, the patients with DCMD showed significantly higher expression of EGFR $(p=0.002)$ and p53 $(\mathrm{p}<0.0001)$ and significantly lower expression of hormone receptors (ER, $\mathrm{p}=0.001$; PgR, $\mathrm{p}=0.002$ ) and HER2/neu $(\mathrm{p}=0.04)$.

Of the 30 patients with DCMD, only two showed overexpression of hormone receptors without overexpression of EGFR. Coexpression of HER2/neu and EGFR was detected in only one patient. EGFR was overexpressed in 13 of 20 patients with immunoreactivity for p53 (table 4).

\begin{tabular}{|c|c|c|c|c|}
\hline & \multicolumn{3}{|c|}{ EGFR } & \multirow[b]{2}{*}{$p$ Value } \\
\hline & + & - & Total & \\
\hline \multicolumn{5}{|l|}{ ER } \\
\hline+ & 1 & 2 & 3 & \\
\hline - & 20 & 7 & 27 & 0.14 \\
\hline \multicolumn{5}{|l|}{$\mathrm{PgR}$} \\
\hline+ & 2 & 2 & 4 & \\
\hline- & 19 & 7 & 26 & 0.35 \\
\hline \multicolumn{5}{|c|}{ HER2 } \\
\hline+ & 1 & 0 & 1 & \\
\hline 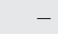 & 20 & 9 & 29 & 0.51 \\
\hline \multicolumn{5}{|l|}{ p53 } \\
\hline+ & 13 & 7 & 20 & \\
\hline - & 8 & 2 & 10 & 0.40 \\
\hline
\end{tabular}

EGFR, epidermal growth factor receptor; ER, oestrogen receptor; PgR, progesterone receptor.

\section{FISH analysis}

FISH analysis revealed that the mean EGFR : CEP7 ratio of the 24 DCMD samples available for evaluation was 1.03, and EGFR gene amplification was not detected in the 21 patients with DCMD in whom EGFR was overexpressed (fig 4). The EGFR gene was not amplified in control cases with overexpression (data not shown).

\section{DISCUSSION}

Metaplastic carcinomas of the breast are rare neoplasms that account for $<5 \%$ of mammary tumours and consist of different mixtures of neoplastic breast epithelial cells and metaplastic elements. Wargotz and Norris divided these

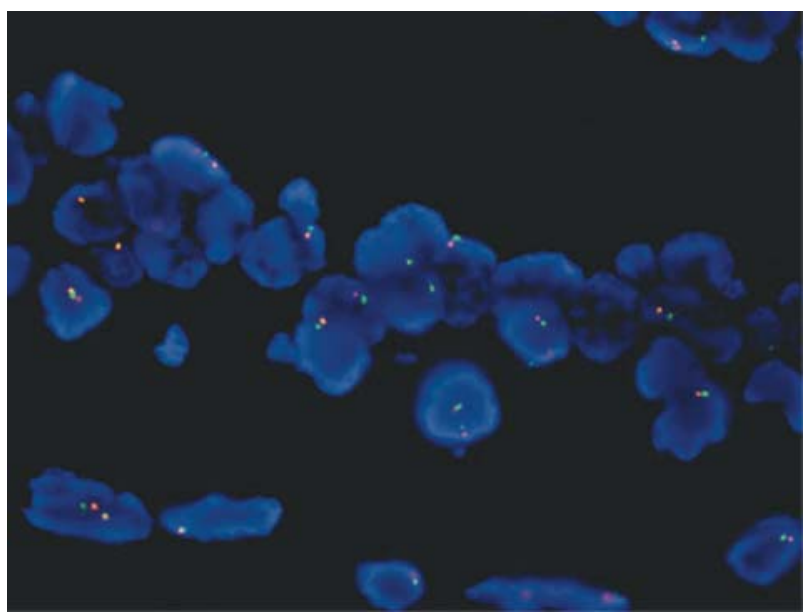

Figure 4 EGFR (epidermal growth factor receptor) gene amplification in high grade ductal carcinomas with myoepithelial differentiation was not detected, despite EGFR overexpression. EGFR, orange signal; CEP7, green signal.

Table 3 Immunohistochemical characteristics of the study patients, controls, and previously described patients with high grade $\mathrm{CIDC}^{9-11}$ 13-18

\begin{tabular}{lllll}
\hline Antigen & DCMD $(\mathbf{n}=\mathbf{3 0})$ & Controls $(\mathbf{n}=\mathbf{3 6})$ & p Value & High grade clDC* \\
\hline EGFR & $21(70 \%)$ & $8(22 \%)$ & 0.002 & $272(20 \%)$ \\
HER2/neu & $1(3 \%)$ & $9(25 \%)$ & 0.04 & $52(30 \%)$ \\
ER & $3(10 \%)$ & $18(50 \%)$ & 0.001 & $37(35 \%)$ \\
PgR & $4(13 \%)$ & $17(47 \%)$ & 0.002 & $7(44 \%)$ \\
p53 & $20(67 \%)$ & $5(14 \%)$ & $<0.0001$ & $55(47 \%)$ \\
\hline
\end{tabular}

CIDC, conventional invasive ductal carcinoma; DCMD, ductal carcinoma with myoepithelial differentiation; EGFR, epidermal growth factor receptor; ER, oestrogen receptor; PgR, progesterone receptor. 
tumours into five subtypes: MPC (I), spindle cell carcinoma (II), CS (III), squamous cell carcinoma of ductal origin (IV), and metaplastic carcinoma with osteoclastic giant cells (V). ${ }^{1451920}$ Tsuda and colleagues ${ }^{6}$ showed that large, central acellular zones indicated myoepithelial differentiation in high grade IDCs. Wargotz and Norris ${ }^{4}$ previously reported that MPCs and CSs showed myoepithelial differentiation. Therefore, we defined DCMD in our study as high grade ductal carcinoma immunohistochemically shown to express myoepithelial markers.

In 16 of the 30 patients with DCMD, metastases were noted in the brain (nine), lungs (lung), bone (five), liver (three), skin (one), stomach (one), spleen (one), and soft tissue (one) within 47 months (mean, 13.9) after initial surgery, whereas only four metastases were noted in the conventional IDC group (two each to the lungs and bone) within 27 months (mean, 18.0) of initial surgery. Tsuda et al reported metastases to the lung, brain, bone, and liver in 13 of 20 IDCs with large central acellular zones. ${ }^{6}$ In the 26 MPCs described by Wargotz and Norris, ${ }^{4}$ nine patients had local recurrence and/or metastasis within 30 months of initial treatment. Five of these patients developed distant metastases to the lung (four), bone (two), and brain (two). Wargotz and Norris ${ }^{5}$ also stated that 34 of 70 patients with CS had local recurrence and/or metastasis within 76 months of initial treatment, and the most common pattern of metastasis was to the pleura, lungs, bone, liver, and brain. Thus, the rate of metastasis and metastatic sites of DCMD in our present study are consistent with those of previous reports.

In our series, immunohistochemical expression of HER2/ neu, ER, and PgR was seen in one, three, and four of 30 patients with DCMD, respectively. In previous reports, none of seven cases of spindle cell carcinoma showed nuclear reactivity for ER or PgR, ${ }^{821} 22$ whereas immunopositivity was seen in two of 30 carcinomas with chondroid metaplasia. ${ }^{8}{ }^{23}$ Bellino et al reported that eight of 11 cases of metaplastic carcinoma were immunopositive for HER2/neu, ${ }^{8}$ whereas Chhieng et al found that only two of 18 cases of metaplastic carcinoma with osteocartilaginous elements overexpressed HER2/neu. ${ }^{23}$ Therefore, the expression rates of ER and PgR in DCMD in our present study are consistent with previous reports, whereas the expression of HER2/neu is lower than that reported previously.

We detected HER2/neu, ER, and PgR expression in nine, 18 , and 17 of the 36 controls, respectively. ER and PgR expression has previously been reported in 37 of $106^{13-15}$ and seven of 16 cases of high grade conventional IDC, respectively. ${ }^{13}$ In addition, HER2/neu overexpression was seen in 52 of 174 cases of high grade conventional IDC. ${ }^{16-18}$ The rate of expression of HER2/neu in our control subjects is consistent with previous reports. There was a significant difference in HER2/neu, ER, and PgR expression between patients with DCMD and controls $(\mathrm{p}<0.05)$.

Immunohistochemical expression of EGFR was seen in 21 of the 30 patients with DCMD, but only in eight of the 36 controls. Chhieng et al found EGFR expression in seven of 18 cases of metaplastic carcinoma with osteocartilaginous elements. ${ }^{23}$ It has been reported that EGFR is expressed in $7-36 \%$ of breast carcinomas with high grade conventional IDC, ${ }^{9-11}$ and EGFR expression was seen in $272(20 \%)$ of the 1388 cases. In a univariate analysis, Tsutsui et al showed a significantly worse clinical outcome for patients with EGFR positive tumours compared with those who were EGFR negative, both for overall survival and DFS. ${ }^{10}$ The rate of expression for EGFR in DCMD in our series was higher than that of previous studies, and it is expected that patients with DCMD have a worse clinical outcome.

Both EGFR and HER2/neu are reportedly overexpressed in high grade conventional IDCs. ${ }^{9-11} 1315$ We found that HER2/ neu overexpression was infrequent, despite the high rate of EGFR overexpression in DCMD. Coexpression of HER2/neu and EGFR was detected in only one case, and EGFR and HER2/neu overexpression appear to be independent events in DCMD.

In our series, p53 was expressed in 20 of the 30 DCMD cases and only five of the 36 control cases. p53 expression was previously reported in 14 of 29 metaplastic carcinomas. ${ }^{823}$ Yamashita et al found p53 expression in 55 (47\%) of 116 cases of high grade conventional IDC. ${ }^{16}$ The rate of expression of $\mathrm{p} 53$ in metaplastic carcinomas and high grade conventional IDC has previously been reported as being similar, but in our series p53 expression was higher in DCMD than that in controls.

Tumours with both HER2/neu overexpression and p53 protein accumulation have been reported in several studies, and patients with such tumours were found to have a poor prognosis. ${ }^{16} 2425$ In addition, earlier studies have shown that the presence of $\mathrm{p} 53$ protein in breast carcinoma is significantly correlated with the overexpression of $\mathrm{EGFR}^{26}{ }^{27}$; however, we did not find a similar correlation in our series, as described previously. ${ }^{28}$

"EGFR and HER2/neu overexpression appear to be independent events in ductal carcinoma with myoepithelial differentiation"

In our series, EGFR gene amplification (assessed by FISH) was not detected in the 21 patients with DCMD and EGFR overexpression. Kersting et al recently reported that FISH revealed a low frequency of EGFR gene amplification, despite protein overexpression, in 222 invasive ductal carcinomas, including 29 high grade carcinomas. ${ }^{29}$ In their report, eight cases $(4.7 \%)$ showed EGFR gene amplification by FISH and 31 cases $(17 \%)$ showed overexpression of EGFR by means of immunohistochemistry. FISH showed EGFR gene amplification in only three of the 23 cases with immunohistochemical protein overexpression, whereas gene amplification was seen in two (1.6\%) of the 124 cases without immunohistochemical protein overexpression. The findings of our series of patients with DCMD corroborate these previous results. Moreover, studies of EGFR gene amplification in other solid tumours have reported lower incidences of gene amplification relative to receptor overexpression, implying that in most solid tumours gene amplification is not the prevailing mechanism of EGFR overexpression, and that it is also unlikely to be of diagnostic value for most solid tumours.

The underlying mechanisms of EGFR protein overexpression are not understood completely. Gene amplification was proposed as a possible mechanism for many years, but recent

Take home messages

- We evaluated the expression of common biological markers and the epidermal growth factor receptor (EGFR) in mammary high grade ductal carcinomas with myoepithelial differentiation (DCMDs)

- EGFR was frequently overexpressed in DCMD compared with high grade conventional invasive ductal carcinoma, whereas HER2/neu and hormone receptors were less frequently expressed in DCMD

- p53 was also overexpressed in DCMD

- Immunohistochemistry for myoepithelial markers and EGFR can be useful for the accurate diagnosis and molecular target treatment of DCMD 
studies indicate that other mechanisms may play a role, such as post-translational changes or the length of polymorphisms in intron 1 of the EGFR gene. ${ }^{29} 30$

In summary, EGFR was frequently overexpressed in DCMD compared with high grade conventional IDC, whereas HER2/ neu and hormone receptors were less frequently expressed in DCMD. p53 was also overexpressed in DCMD. In suspected cases of DCMD, immunohistochemical examination for myoepithelial markers and EGFR can be useful for the accurate diagnosis and molecular target treatment of this special type of mammary ductal carcinoma with a different metastatic pattern and prognosis.

\section{ACKNOWLEDGEMENTS}

This work was supported by a Grant-in-Aid for Cancer Research (166) from the Ministry of Health, Labour and Welfare of Japan.

\section{Authors' affiliations}

T Shien, S Akashi-Tanaka, M Uehara, E Iwamoto, T Kinoshita, T Fukutomi, Division of Surgical Oncology, National Cancer Centre Hospital, Tokyo 104-0045, Japan

T Tashiro, M Omatsu, T Masuda, K Furuta, Division of Clinical Laboratory, National Cancer Centre Hospital

N Sato, Division of Diagnostic Radiology, National Cancer Centre Hospital

H Tsuda, Department of Clinical Pathology, National Defence Medical College, Saitama 359-8513, Japan

T Hasegawa, Department of Clinical Pathology, Sapporo Medical University School of Medicine, Sapporo 060-8543, Japan

\section{REFERENCES}

1 Wargotz ES, Deos PH, Norris HJ. Metaplastic carcinomas of the breast. II. Spindle cell carcinoma. Hum Pathol 1989;20:732-40.

2 Dunne B, Lee AH, Pinder SE, et al. An immunohistochemical study of metaplastic spindle cell carcinoma, phyllodes tumor and fibromatosis of the breast. Hum Pathol 2003;34:1009-15.

3 Jones C, Nonni AV, Fulford L, et al. CGH analysis of ductal carcinoma of the breast with basaloid/myoepithelial cell differentiation. $\mathrm{Br} J$ Cancer 2001;85:422-7.

4 Wargotz ES, Norris HJ. Metaplastic carcinomas of the breast. I. Matrixproducing carcinoma. Hum Pathol 1989;20:628-35.

5 Wargotz ES, Norris HJ. Metaplastic carcinomas of the breast. III. Carcinosarcoma. Cancer 1989;64:1490-9.

6 Tsuda H, Takarabe T, Hasegawa F, et al. Large, central acellular zones indicating myoepithelial tumor differentiation in high-grade invasive ductal carcinomas as markers of predisposition to lung and brain metastases. Am J Surg Pathol 2000;24:197-202.

7 Tsuda H, Takarabe T, Hasegawa T, et al. Myoepithelial differentiation in highgrade invasive ductal carcinomas with large central acellular zones. Hum Pathol 1999;30:1134-9

8 Bellino R, Arisio R, D'Addato F, et al. Metaplastic breast carcinoma: pathology and clinical outcome. Anticancer Res 2003;23:669-73.

9 Chung GG, Zerkowski MP, Ocal IT, et al. Beta-catenin and p53 analyses of a breast carcinoma tissue microarray. Cancer 2004;100:2084-92.
10 Tsutsui S, Ohno S, Murakami S, et al. Prognostic value of epidermal growth factor receptor (EGFR) and its relationship to the estrogen receptor status in 1029 patients with breast cancer. Breast Cancer Res Treat 2002;71:67-75.

11 Walker RA, Dearing SJ. Expression of epidermal growth factor receptor mRNA and protein in primary breast carcinomas. Breast Cancer Res Treat 1999;53:167-76.

12 Averbuch S, Kcenler M, Morris C, et al. Therapeutic potential of tyrosine kinase inhibitors in breast cancer. Cancer Invest 2003;21:782-91.

$13 \mathrm{Xu}$ R, Feiner $\mathrm{H}$, Li P, et al. Differential amplification and overexpression of HER-2/neu, p53, MIB1, and estrogen receptor/progesterone receptor among medullary carcinoma, atypical medullary carcinoma, and high-grade invasive ductal carcinoma of breast. Arch Pathol Lab Med 2003;127:1458-64.

14 Jensen ML, Kiaer H, Melsen F. Medullary breast carcinoma vs. poorly differentiated ductal carcinoma: an immunohistochemical study with keratin 19 and oestrogen receptor staining, Histopathology 1996;29:241-5.

15 Hammock L, Lewis $M$, Phillips $C$, et al. Strong HER-2/neu protein overexpression by immunohistochemistry often does not predict oncogene amplification by fluorescence in situ hybridization. Hum Pathol 2003;34:1043-7

16 Yamashita H, Nishio M, Toyama T, et al. Coexistence of HER2 overexpression and $\mathrm{p} 53$ protein accumulation is a strong prognostic molecular marker in breast cancer. Breast Cancer Res 2004;6:R24-30.

17 Saver T, Wiedswang G, Boudjema G, et al. Assessment of HER-2/neu overexpression and/or gene amplification in breast carcinomas: should in situ hybridization be the method of choice? APMIS 2003;111:444-50.

18 Latta EK, Tjan S, Parkes RK, et al. The role of HER2/neu overexpression/ amplification in the progression of ductal carcinoma in situ to invasive carcinoma of the breast. Mod Pathol 2002;15:1318-25.

19 Wargotz ES, Norris HJ. Metaplastic carcinomas of the breast. IV. Squamous cell carcinoma of ductal origin. Cancer 1990;65:272-6.

20 Wargotz ES, Norris HJ. Metaplastic carcinomas of the breast: V. Metaplastic carcinoma with osteoclastic giant cells. Hum Pathol 1990;21:1142-50.

21 Chao TC, Wang CS, Chen SC, et al. Metaplastic carcinomas of the breast. J Surg Oncol 1999;71:220-5.

22 Oberman HA. Metaplastic carcinoma of the breast. A clinicopathologic study of 29 patients. Am J Surg Pathol 1987; 11:918-29.

23 Chhieng $C$, Cranor M, Lesser ME, et al. Metaplastic carcinoma of the breast with osteocartilaginous heterologous elements. Am J Surg Pathol 1998;22:188-94

24 Rahko E, Blanco G, Soini $Y$, et al. A mutant TP53 gene status is associated with a poor prognosis and anthracycline-resistance in breast cancer patients. Eur J Cancer 2003;39:447-53.

25 Beenken SW, Grizzle WE, Crowe DR, et al. Molecular biomarkers for breast cancer prognosis: coexpression of c-erbB-2 and p53. Ann Surg 2001;233:630-8.

26 Walker RA, Dearing SJ, Lane DP, et al. Expression of p53 protein in infiltrating and in-situ breast carcinomas. J Pathol 1991;165:203-1 1

27 Poller DN, Hutchings CE, Galea M, et al. p53 protein expression in human breast carcinoma: relationship to expression of epidermal growth factor receptor, c-erbB-2 protein overexpression, and oestrogen receptor. Br J Cancer 1992;66:583-8.

28 Horne GM, Anderson JJ, Tiniakos DG, et al. p53 protein as a prognostic indicator in breast carcinoma: a comparison of four antibodies for immunohistochemistry. Br J Cancer 1996;73:29-35.

29 Kersting C, Tidow N, Schmidt H, et al. Gene dosage PCR and fluorescence in situ hybridization reveal low frequency of egfr amplifications despite protein overexpression in invasive breast carcinoma. Lab Invest 2004;84:582-7.

30 Buerger $H$, Packeisen J, Boecker A, et al. Allelic length of a CA dinucleotide repeat in the egfr gene correlates with the frequency of amplifications of this sequence - first results of an inter-ethnic breast cancer study. J Pathol 2004;203:545-50 